\title{
Augmenter of liver regeneration ameliorates ischemia-reperfusion injury in steatotic liver via inhibition of the TLR4/NF-kB pathway
}

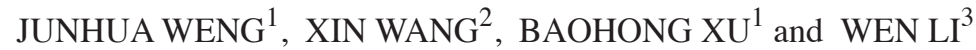 \\ ${ }^{1}$ Department of Gastroenterology, ${ }^{2}$ Beijing Key Laboratory of Diabetes Research and Care Center for \\ Endocrine Metabolism and Immune Diseases, Beijing Lu He Hospital, Capital Medical University, Beijing 101149; \\ ${ }^{3}$ Department of Cell Biology and Municipal Laboratory of Liver Protection and Regulation of Regeneration, \\ Capital Medical University, Beijing 100069, P.R. China
}

Received October 2, 2020; Accepted May 17, 2021

DOI: $10.3892 / \mathrm{etm} .2021 .10295$

\begin{abstract}
Hepatocytes from donors with preexisting hepatic steatosis exhibited increased sensitivity to ischemia-reperfusion injury (IRI) during liver transplantation. Augmenter of liver regeneration (ALR) protected the liver against IRI, but the mechanism was not clarified. Therefore, the hypothesis that ALR attenuated IRI in steatotic liver by inhibition of inflammation and downregulation of the Toll-like receptor 4 (TLR4)/nuclear factor- $\kappa \mathrm{B}(\mathrm{NF}-\kappa \mathrm{B})$ pathway was examined. C57BL/6 mice were subjected to a methionine-choline-deficient (MCD) diet to induce liver steatosis. Mice were transfected with ALR-containing adenovirus 3 days prior to partial warm hepatic IRI. After $30 \mathrm{~min}$ of ischemia and $6 \mathrm{~h}$ of reperfusion injury, liver function, hepatic injury, the inflammatory response and TLR4/NF- $\mathrm{KB}$ signaling pathway activation were assessed. ALR maintained liver function and alleviated hepatic injury as indicated by the decreased levels of serum alanine aminotransferase (ALT) and aspartate aminotransferase (AST), preserved hepatic structure and reduced apoptosis. ALR also reduced the IRI-induced inflammatory response by suppressing Kupffer cell activation, inhibiting neutrophil chemotaxis and reducing inflammatory
\end{abstract}

Correspondence to: Dr Baohong $\mathrm{Xu}$, Department of Gastroenterology, Beijing Lu He Hospital, Capital Medical University, 82 Xinhua South Road, Beijing 101149, P.R. China E-mail: bhxu22@126.com

Dr Wen Li, Department of Cell Biology and Municipal Laboratory of Liver Protection and Regulation of Regeneration, Capital Medical University, 10 You-An-Men Wai-Xi-Tou-Tiao, Beijing 100069, P.R. China

E-mail: liwenrose@163.com

Abbreviations: ALR, augmenter of liver regeneration; IRI, ischemia-reperfusion injury; $\mathrm{MCD}$, methionine-choline-deficient;

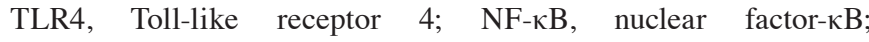
MPO, myeloperoxidase; F4/80, mouse EGF-like module-containing mucin-like hormone receptor-like 1

Key words: augmenter of liver regeneration, ischemia-reperfusion injury, Toll-like receptor $4, \mathrm{NF}-\kappa \mathrm{B}$, fatty liver cytokine production. Further investigation using reverse transcription-quantitative PCR, western blotting and immunohistochemistry revealed that ALR reduced TLR4/NF- $\kappa \mathrm{B}$ signaling pathway activation, which led to a decreased synthesis of inflammatory cytokines. ALR functioned as a regulator of the IRI-induced inflammatory response by suppressing the TLR4/NF- $\kappa$ B pathway, which supports the use of ALR in therapeutic applications for fatty liver transplantation.

\section{Introduction}

Hepatic ischemia-reperfusion injury (IRI) is the phenomenon in which hepatocellular damage is aggravated after the reperfusion of blood flow in the liver (1). Hepatic IRI occurs in numerous clinical situations, such as liver transplantation, liver resection, trauma, shock and hemorrhage $(2,3)$. The incidence of nonalcoholic fatty liver disease (NAFLD) has markedly increased and is currently estimated at approximately 20-30\% in the general population and up to $70-80 \%$ in the obese population (4). An increasing trend of IRI in fatty liver is predicted in the near future (3). Clinical studies and animal experiments revealed that steatotic livers are particularly susceptible to IRI (5). Fatty liver grafts are associated with a primary non-function rate of $60 \%$ compared to $5 \%$ for non-steatotic grafts and increase the risk of postoperative morbidity and mortality after fatty liver surgery $(6,7)$. However, there are few effective methods to reduce the susceptibility of fatty liver to IRI. Recent studies demonstrated that inflammation played an important role in the process of fatty liver IRI, including more obvious inflammatory cell infiltration and inflammatory factor release (8-10).

Toll-like receptors (TLRs) form a part of the host innate immune system that triggers the innate immune response and production of inflammatory mediators (11). TLR4 is a key TLR family member that is an essential participant in hepatic IRI. TLR4 is ubiquitously expressed in hepatocytes and nonparenchymal cells $(12,13)$. TLR4 activation initiates signal transduction pathways. Then, transcription factors such as NF- $\kappa$ B are activated and cytokines are produced (14). TLR4-deficient mice have decreased levels of inflammatory cytokines and are significantly protected against hepatic IRI (15). 
Augmenter of liver regeneration (ALR), also referred to as hepatic stimulator substance (HSS), was first identified for its promotion of liver regeneration after partial hepatectomy (16). ALR plays an important role in protecting hepatocytes against various injuries by reducing endoplasmic reticulum stress and improving mitochondrial function $(17,18)$. A previous study has revealed that ALR also reduced the inflammatory response. ALR reduced the infiltration of $\mathrm{CD} 4^{+} \mathrm{T}$ cells and neutrophils to alleviate normal liver IRI (19). However, the relationship between ALR and the inflammatory response in fatty liver IRI and the underlying mechanisms remain unclear. It was hypothesized that ALR protects against fatty liver IRI via inhibition of the TLR4/NF- $\kappa$ B pathway to reduce inflammatory cell infiltration and inflammatory factor release.

\section{Materials and methods}

Animals and model of fatty liver IRI. Experiments were performed on male C57BL/6 mice (age 6-8 weeks; weight $\sim 18-22 \mathrm{~g}$ ) that were purchased from the Academy of Military Sciences (Beijing, China). All animals were treated humanely according to the Guidelines for Animal Care and Use in Medical Research (20) and the experimental methods are approved by The Ethics Committee of Capital Medical University (Beijing, China; approval no. AEEI-2016-094). A total of 30 male mice were housed at a constant room temperature $\left(22-25^{\circ} \mathrm{C}\right)$, a relative humidity of $40-60 \%$ under a $12 / 12 \mathrm{~h}$ light-dark cycle with access to water and food ad libitum. Mice were fed a methionine-choline-deficient (MCD) diet (Beijing HFK Bioscience Co., Ltd.) for 2 weeks, and then underwent warm liver IRI $(21,22)$, while the control mice were fed an isocaloric control diet. Briefly, mice were anesthetized with $4 \%$ chloral hydrate intraperitoneally $(320 \mathrm{mg} / \mathrm{kg})$, and the artery/portal vein blood flow to the left and middle lobes of the liver was temporarily interrupted using an atraumatic clip, which induced $\sim 70 \%$ liver ischemia. Liver ischemia was maintained for $30 \mathrm{~min}$, and the clip was loosened to allow reperfusion for $6 \mathrm{~h}$. Mice in the sham-operated group underwent the same surgical procedure without clamping of the hepatic vessels. At the end of the experiments, mice were sacrificed by inhalation of anesthetics in a closed chamber (e.g. an overdose of 5\% isoflurane). Mice continued to be exposed to isoflurane until they stopped breathing for $1 \mathrm{~min}$, and then they were removed from the chamber to confirm death through the absence of a heartbeat and nerve reflexes. Blood samples were collected from the inferior vena cava, and liver tissues were prepared for further analysis.

Gene transfer. Human ALR cDNA was cloned into a replication-deficient adenoviral vector with the flag tag as previously described (21). Three days before IRI, mice subjected to an MCD diet were randomly divided into 4 groups: 3 groups were injected with Adnull (control virus, $1 \times 10^{9} \mathrm{PFU} / \mathrm{mouse}$ ), AdALR ( $\left.1 \times 10^{9} \mathrm{PFU} / \mathrm{mouse}\right)$ or normal saline (NS) via the tail vein. Sham-operated mice served as controls.

Biochemical assays and triglyceride determination. The activities of serological alanine aminotransferase (ALT) and aspartate aminotransferase (AST) and the concentrations of serological triglyceride (TG) were analyzed using an automatic biochemical analyzer (Hitachi, Ltd.) at the Clinical Laboratory Center of Capital Medical University. The TG content in liver tissue was determined using a TG kit (cat. no. K622; Biovision, Inc.) according to the manufacturer's protocol.

Enzyme-linked immunosorbent assay (ELISA). The levels of interleukin (IL)-1 $\beta$, IL-6, and tumor necrosis factor- $\alpha$ (TNF- $\alpha$ ) in murine serum were assessed using commercially available ELISA kits (cat. nos. MLB00C, M6000B, MTA00B, respectively; R\&D Systems, Inc.) according to the manufacturer's protocol based on the quantitative sandwich enzyme immunoassay technique. Briefly, $50 \mu \mathrm{l}$ of murine serum was incubated in ELISA plates at room temperature for $2 \mathrm{~h}$. After washing with washing buffer, $100 \mu$ l of conjugated antibody was added and incubated at room temperature for another $2 \mathrm{~h}$. The substrate solution was added and incubated for $20 \mathrm{~min}$ in the dark, followed by the addition of a stopping solution. The optical density (OD) was measured at $450 \mathrm{~nm}$, and the concentrations of the cytokines were calculated by reference to the standard curves.

Histology and Oil Red $O$ staining. Liver tissues from the ischemic lobes were fixed in $10 \%$ buffered formalin for $24 \mathrm{~h}$ at room temperature and embedded in paraffin. For hematoxylin and eosin (H\&E; 200X) staining, sections of 5- $\mu \mathrm{m}$ thickness were stained in hematoxylin for $5 \mathrm{~min}$ at room temperature, then transferred to $1 \%$ hydrochloric acid alcohol for differentiation and washed in running water for $2 \mathrm{~min}$. After soaking in the eosin stain for $3 \mathrm{~min}$ at room temperature, sections were washed in running water. The Suzuki score was used to evaluate liver injury based on 3 indices: sinusoidal congestion, hepatocyte necrosis and ballooning degeneration (23). To evaluate the intracellular lipid distribution in the liver, liver samples were fixed in $4 \%$ paraformaldehyde for $24 \mathrm{~h}$ at room temperature frozen in liquid nitrogen and sectioned into $6-\mu \mathrm{m}$ slices. Sections were stained in Oil Red O solution for $15 \mathrm{~min}$ at room temperature, rinsed with $60 \%$ isopropanol, stained with hematoxylin at room temperature for $30 \mathrm{sec}$, and images were captured using light microscopy (magnification, x100).

Immunohistochemistry. Immunohistochemical staining was performed as previously described (21). Briefly, the liver tissue sections $(5-\mathrm{mm})$ were dewaxed, hydrated and pretreated using the heat-induced antigen retrieval technique. Sections were treated sequentially with a $3 \% \mathrm{H}_{2} \mathrm{O}_{2}$ solution and 5\% BSA to block endogenous peroxidase activity and nonspecific antibody binding, respectively. Primary antibodies directed against ALR (1:500; cat. no. 11293-1-AP; Proteintech Group, Inc.), mouse EGF-like module-containing mucin-like hormone receptor-like 1 (F4/80; 1:200; cat. no. ab6640; Abcam), myeloperoxidase (MPO; 1:200; cat. no. ab90810; Abcam), proliferating cell nuclear antigen (PCNA; 1:500; cat. no. 13110; Cell Signaling Technology, Inc.), TLR4 (1:100; cat. no. sc-293072; Santa Cruz Biotechnology, Inc.) and NF- $\kappa$ B p65 (1:200; cat. no. 8242; Cell Signaling Technology, Inc.) were incubated with the sections overnight at $4^{\circ} \mathrm{C}$, followed by HRP-conjugated IgG incubation (1:200; cat. no. SA00001-2; ProteinTech Group, Inc.) Sections were visualized with diaminobenzidine (DAB) and counterstained with hematoxylin. The positively stained areas and positive cells were evaluated using 
Image-Pro Plus 6.0 software (Media Cybernetics Inc.). Staining was quantified in 10 randomly selected x 200 high-power fields per tissue sample.

To detect cellular apoptosis in liver tissue, a terminal deoxynucleotidyltransferase (dUTP)-mediated nick endlabeling (TUNEL) assay was performed using an In Situ Cell Death/Apoptosis Detection kit (cat. no. 11684817910; Roche Diagnostics, $\mathrm{GmbH}$ ) according to the manufacturer's protocol. Briefly, the liver tissue sections were dewaxed in an incubator at $60^{\circ} \mathrm{C}$ for 20 min followed by deparaffinization in xylene for $10 \mathrm{~min}$, and then were soaked in 100, 95, 90, 80 and $70 \%$ gradient alcohol for $5 \mathrm{~min}$ each at room temperature for rehydration. Slides were incubated with Proteinase K working solution for $20 \mathrm{~min}$ at room temperature, followed by incubation with TUNEL reaction mixture for $60 \mathrm{~min}$ at $37^{\circ} \mathrm{C}$ in the dark. Next, Converter-POD antibody (1:500) from aforementioned TUNEL kit was used for further reaction for $30 \mathrm{~min}$ at $37^{\circ} \mathrm{C}$, followed by the addition of DAB substrate for $10 \mathrm{~min}$ at room temperature. The sections were then counterstained with hematoxylin at room temperature for $2 \mathrm{~min}$ and mounted using glycerol. The results were scored semi-quantitatively by averaging the numbers of TUNEL-positive cells per high-power field (magnification, x200) for 10 fields per tissue sample with ImageJ 1.5 software (National Institutes of Health).

Cytoplasmic and nuclear protein extraction. Cytoplasmic and nuclear protein extraction was performed using a commercial kit (NT-032; Invent Biotechnologies, Inc.) according to the manufacturer's instructions. Briefly, 20-30 mg liver tissue was grinded with a pestle in $250 \mu \mathrm{l}$ buffer A for approximately $1 \mathrm{~min}$. After centrifugation at $14,000 \mathrm{x}$ g for $5 \mathrm{~min}$ at $4^{\circ} \mathrm{C}$, a total of $200 \mu \mathrm{l}$ of supernatant was collected and stored as the cytosolic fraction. The pellet was grinded 60-100 times with the pestle, followed by the addition of $0.8 \mathrm{ml}$ buffer $\mathrm{A}$ and grinded a few more times. After incubation on ice for $8 \mathrm{~min}$, a total of $0.7 \mathrm{ml}$ of supernatant was transferred to a fresh tube and centrifuged at $500 \mathrm{x} \mathrm{g}$ for $2 \mathrm{~min}$ at $4^{\circ} \mathrm{C}$. Then the pellet was resuspended in $0.5 \mathrm{ml}$ buffer B by vortex for $20 \mathrm{sec}$ and incubated on ice for $5 \mathrm{~min}$. After centrifugation at $2,000 \mathrm{x}$ g for $2 \mathrm{~min}$ at $4^{\circ} \mathrm{C}$, nuclear extracts were collected for further analysis.

Western blot analysis. Immunoblotting was performed as previously described (17). Briefly, liver tissues were homogenized, and samples containing $50 \mu \mathrm{g}$ of protein were loaded and transferred to PVDF membranes. The following primary antibodies (all at 1:1,000) were used for immunoblotting: Flag tag (cat. no. F9291; Sigma-Aldrich; Merck KGaA), ALR, TLR4 and $\mathrm{NF}-\kappa \mathrm{B}$ p65. Antibodies against glyceraldehyde 3-phosphate dehydrogenase (GAPDH; 1:5,000; 10494-1-AP; ProteinTech Group, Inc.) and $\beta$-actin (1:5,000; cat. no. 20536-1-AP; ProteinTech Group, Inc.) were used as the loading controls. Membranes were then incubated with horseradish peroxidase (HRP)-conjugated goat anti-rabbit IgG secondary antibodies (1:5,000; cat. no. SA00001-2; ProteinTech Group, Inc.) for 1 $\mathrm{h}$ at room temperature. The relative densities of the protein bands were quantitatively determined using ImageJ 1.5 software (National Institutes of Health).

Reverse transcription-quantitative (RT-q) PCR. Total RNA was extracted from liver tissue using TRIzol reagent (Invitrogen;
Thermo Fisher Scientific, Inc.) according to the manufacturer's instructions. A total of $2 \mu \mathrm{g}$ of RNA was reversely transcribed to cDNA using a cDNA synthesis kit (cat. no. 6215A; Takara Bio, Inc.) according to the manufacturer's instructions. Quantitative PCR was performed (ABI7500) using SYBR-Green mix (Qiagen $\mathrm{GmbH})$. The thermocycling conditions were as follows: $95^{\circ} \mathrm{C}$ For $5 \mathrm{~min}$ for pre-denaturation; 40 cycles of $95^{\circ} \mathrm{C}$ for $15 \mathrm{sec}$, $60^{\circ} \mathrm{C}$ for $1 \mathrm{~min}$ and $72^{\circ} \mathrm{C}$ for $45 \mathrm{sec} .18 \mathrm{~S}$ rRNA was amplified in parallel as an internal control. The $2^{-\Delta \Delta \mathrm{Cq}}$ method was used to determine the relative mRNA level (24).The primers used are mentioned in Table SI.

Statistical analysis. The experimental results are expressed as the means \pm standard deviations (SDs) of three independent experiments. For multiple comparisons, one-way analysis of variance (ANOVA) followed by Tukey's post hoc test was performed using GraphPad Prism 6 software (GraphPad Software, Inc.). $\mathrm{P}<0.05$ was considered to indicate a statistically significant difference.

\section{Results}

ALR expression is downregulated during IRI in steatotic liver. After 2 weeks of MCD diet feeding, mice were subjected to hepatic IRI, i.e., $30 \mathrm{~min}$ of ischemia followed by $6 \mathrm{~h}$ of reperfusion. The expression of endogenous ALR was evaluated using western blot analysis. The results demonstrated that IRI decreased the expression of ALR (Fig. 1A), which indicated that ALR is involved in IRI. Adenovirus-mediated gene transfer of ALR was performed in mice 3 days before IRI. Exogenously delivered ALR was expressed efficiently within the liver, as determined by western blotting (Fig. 1B) and immunostaining (Fig. 1C). Mice fed the MCD diet exhibited elevated TG levels in liver tissues and mild-to-moderate hepatic steatosis, as evidenced by Oil Red O staining $(\mathrm{P}<0.01$; Fig. 1E and F). Adenovirus-mediated ALR gene transfer did not alter TG levels in the blood (Fig. 1D).

ALR expression maintains liver function and attenuates IRI in steatotic liver. Hepatocellular function was evaluated by measuring serum ALT and AST levels. These levels were significantly decreased following IRI in the $\operatorname{Ad} A L R$ group compared with the Adnull group (serum ALT: $395 \pm 42$ vs. $1163 \pm 138 \mathrm{U} / 1, \mathrm{P}<0.01$; serum AST: $539 \pm 69$ vs. $1214 \pm 145 \mathrm{U} / 1, \mathrm{P}<0.01$ ) (Fig. $2 \mathrm{~A}$ and $\mathrm{B}$ ). The liver histology was associated with the serum indices. IRI significantly induced hepatic damage, as indicated by the severe sinusoidal congestion, hepatocellular necrosis and cytoplasmic vacuolization. However, hepatic damage was significantly reduced in the AdALR group compared with the Adnull group and the NS group (Fig. 2C). The Suzuki score was used for histological evaluation of hepatic injury, and these scores also confirmed the protective role of ALR against hepatic IRI ( $\mathrm{P}<0.05$; Fig. 2D). A TUNEL assay was performed to evaluate cellular apoptosis. Few TUNEL-positive cells were observed in the sham group, but significantly increased numbers were observed in the Adnull and NS groups after hepatic IRI. Conversely, the number of TUNEL-positive hepatocytes was decreased in the AdALR group compared with the NS and Adnull groups, which indicated that ALR expression protected hepatocytes 

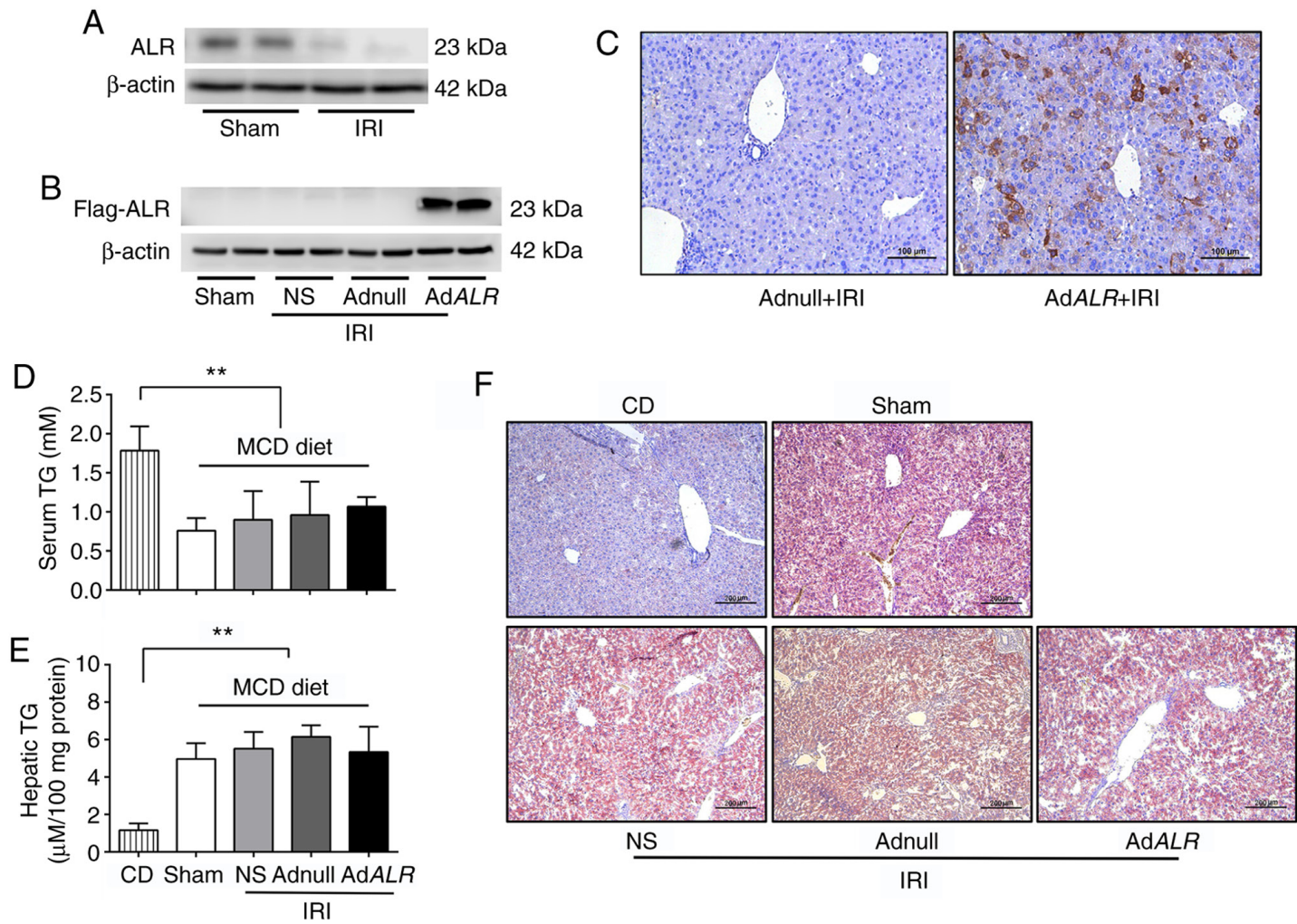

Figure 1. Expression of ALR is downregulated and related to IRI in steatotic liver. C57BL/6 mice were fed an MCD diet for 2 weeks, and control mice were fed an isocaloric control diet. Mice fed the MCD diet were divided into 4 groups. Sham-operated mice served as controls, and the other 3 groups received normal saline, Adnull (control virus) or AdALR gene transfer 3 days before being subjected to IRI, i.e., 30 min of ischemia followed by 6 h of reperfusion. (A) Expression of endogenous ALR in the liver was detected using western blotting. (B and C) Expression of exogenously delivered ALR was detected using western blotting and immunohistochemistry. Scale bars, $10 \mu \mathrm{m}$. (D) Serum TG levels in mice. (E) Liver tissue TG levels in mice. (F) Oil Red O staining of liver sections. Scale bars, $200 \mu \mathrm{m} .{ }^{* *} \mathrm{P}<0.01$; $\mathrm{n}=6$ per group. ALR, augmenter of liver regeneration; IRI, ischemia-reperfusion injury; MCD, methionine-choline-deficient; CD, isocaloric control diet; NS, normal saline; TG, triglyceride.

against IRI-induced cell death $(\mathrm{P}<0.01$; Fig. $2 \mathrm{E}$ and $\mathrm{F})$. The hepatocyte proliferation is demonstrated in Fig. 2G. The number of the proliferating cells in the ALR-transfected mice were increased compared with the Adnull and NS mice, which indicated that ALR enhanced cell growth in the liver after IRI $(\mathrm{P}<0.01$; Fig. $2 \mathrm{G}$ and $\mathrm{H})$.

ALR expression decreases the infiltration of inflammatory cells and the production of inflammatory mediators. Kupffer cell (KCs) activation, as indicated by F4/80 staining, was the early inflammatory response during hepatic IRI. The F4/80-positive area was significantly increased in the IRI groups, and the activation of KCs was decreased in $\operatorname{Ad} A L R$ mice compared with Adnull mice after IRI ( $\mathrm{P}<0.01$; Fig. $3 \mathrm{~A})$. MPO is abundantly expressed in neutrophils and is used as a marker of neutrophil infiltration (25). The number of MPO-positive cells was increased following IRI, and neutrophil infiltration in IRI-induced fatty livers was effectively suppressed in the $\operatorname{Ad} A L R$ group compared with the Adnull and NS groups $(\mathrm{P}<0.01$; Fig. $3 \mathrm{~B})$. Inflammatory cytokines play key roles in the pathophysiology of hepatic IRI (26). The serum levels of IL-1 $\beta$, IL- 6 , and TNF- $\alpha$ were assessed using ELISA (Fig. 3C-E). After IRI, serum IL-1 $\beta$, IL-6 and TNF- $\alpha$ levels were significantly increased in the IRI groups compared with the sham-operated group but were significantly decreased in the AdALR group compared with the Adnull and NS groups $(\mathrm{P}<0.05)$.
ALR modulates the TLR4/NF- $\kappa B$ signaling pathway during IRI in steatotic liver. TLR4 is ubiquitously expressed in the liver, and it initiates the sterile inflammatory response following IRI. TLR4 activation eventually leads to the activation and nuclear translocation of NF- $\kappa \mathrm{B}$ (27). To further understand the inflammation-regulatory role of ALR, RT-qPCR was used to observe the expression of TLR4 and NF- $\mathrm{B}$ p 65 in hepatic IRI. The mRNA levels of TLR4 and NF- $\mathrm{B}$ p 65 were significantly increased in the NS and Adnull groups after IRI compared with the sham-operated group. However, the mRNA levels of TLR4 and $\mathrm{NF}-\kappa \mathrm{B}$ in the $\mathrm{Ad} A L R$ group were significantly decreased compared with the NS and Adnull groups $(\mathrm{P}<0.01$ and $\mathrm{P}<0.05$; Fig. 4A and B). ALR expression inhibited the expression of TLR4 and NF- $\kappa$ B p65 after IRI, as demonstrated by western blot analysis $(\mathrm{P}<0.05$ and $\mathrm{P}<0.01$, respectively; Fig. $4 \mathrm{C}$ and $\mathrm{D})$. The nuclear fraction was extracted to detect the nuclear distribution of $N F-\kappa B$. The results revealed that the levels of nuclear NF- $\mathrm{NB}$ p65 were significantly increased in the NS and Adnull groups compared with the sham-operated group. However, ALR transfection decreased the nuclear NF- $\kappa \mathrm{B}$ p65 $(\mathrm{P}<0.05$; Fig. 4E) compared with the NS and Adnull groups. Immunohistochemistry was also used to detect the expression of TLR4 and NF- $\kappa \mathrm{B}$ during hepatic IRI. After IRI, the expression levels of these proteins were significantly increased in the NS and Adnull groups compared with the sham-operated group but were significantly decreased in the $\operatorname{Ad} A L R$ group $(\mathrm{P}<0.01$; Fig. 4F and $\mathrm{G})$ compared with the NS and Adnull 
A

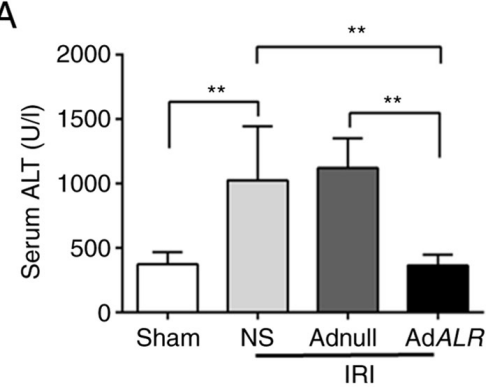

B

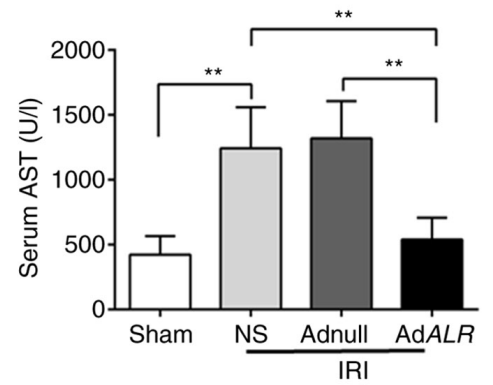

D

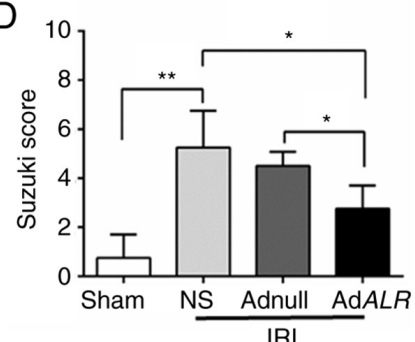

$\mathrm{F}$

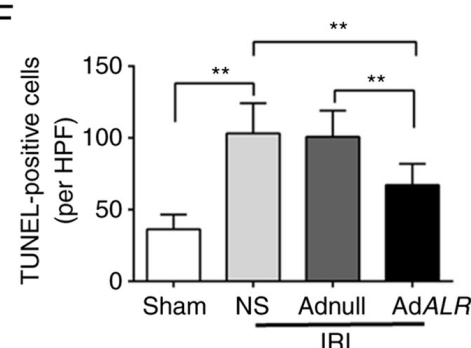

$\mathrm{H}$

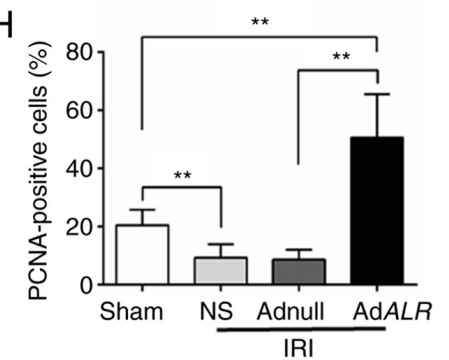

C
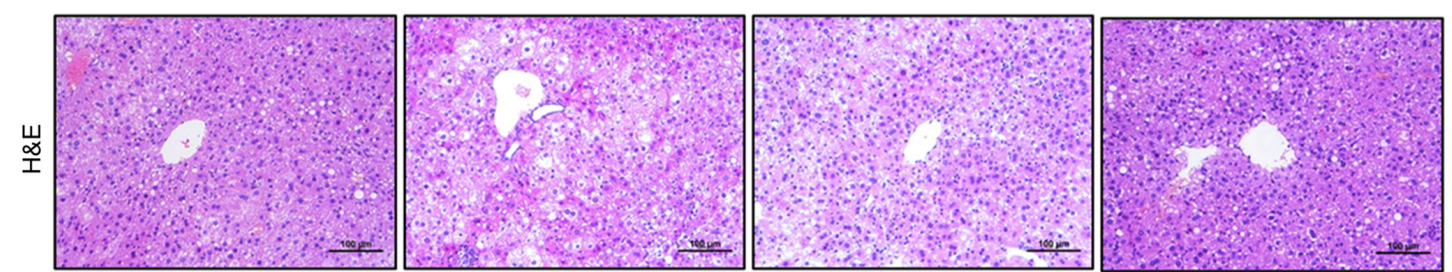

$\mathrm{E}$
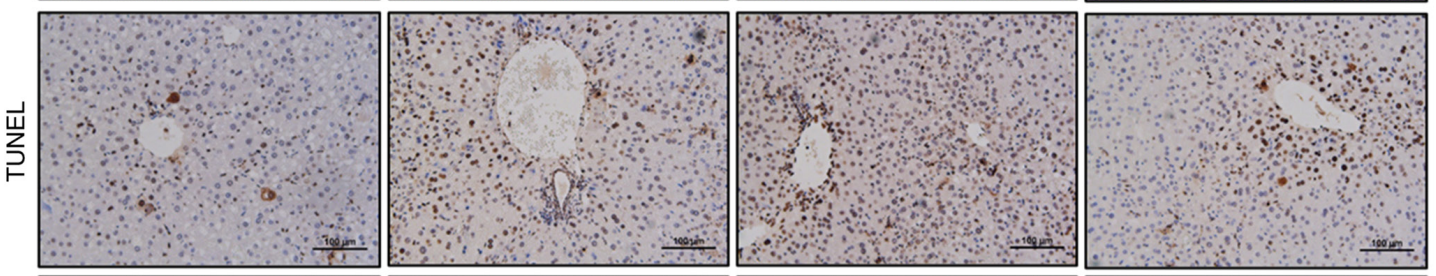

G
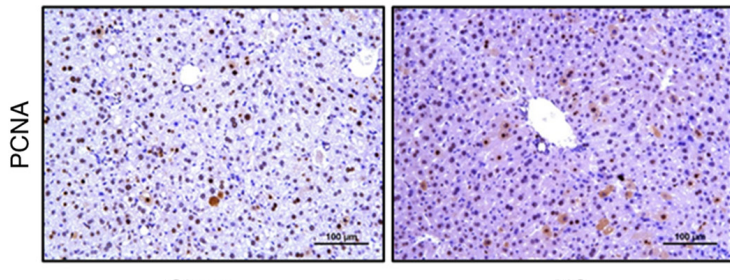

NS
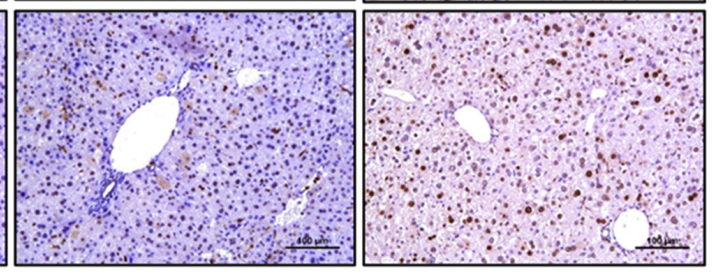

Adnull

$\operatorname{Ad} A L R$

$\mid \mathrm{RI}$

Figure 2. ALR administration decreases liver injury and cellular apoptosis in steatotic livers after IRI. C57BL/6 mice were fed a methionine-choline-deficient diet for 2 weeks then subjected to IRI, i.e., 30 min of ischemia followed by $6 \mathrm{~h}$ of reperfusion. (A and B) Serum levels of the enzymes ALT and AST. (C and D) H\&E staining of liver tissue and histological evaluation of liver damage using the Suzuki score. (E and F) TUNEL assay of apoptosis in fatty livers after IRI and number of TUNEL-positive cells was analyzed. (G and H) Immunohistochemical staining of PCNA was performed, and number of PCNA-positive cells was analyzed. Scale bars, $100 \mu \mathrm{m}$. ${ }^{*} \mathrm{P}<0.05$ and ${ }^{* *} \mathrm{P}<0.01 ; \mathrm{n}=6$ per group. ALR, augmenter of liver regeneration; IRI, ischemia-reperfusion injury; ALT, alanine aminotransferase; AST, aspartate aminotransferase; H\&E, hematoxylin-eosin; TUNEL, terminal deoxynucleotidyl transferase dUTP nick end labeling; NS, normal saline.

groups. These results indicated that ALR suppressed the TLR4 inflammatory signaling cascade during hepatic IRI.

\section{Discussion}

The present study evaluated the effects of ALR on the inflammatory response during fatty liver IRI. The key findings are summarized as follows: i) ALR expression was reduced in steatotic livers during IRI; ii) adenovirus-mediated ALR transfection maintained liver function and alleviated IRI in steatotic livers by suppressing inflammatory cell inflation and reducing inflammatory cytokine production; and iii) ALR played a regulatory role in the inflammatory response during fatty liver IRI via inhibition of the TLR4/NF- $\mathrm{KB}$ signaling pathway.

Although ALR was initially reported as a mitogenic factor that promoted liver regeneration after partial hepatectomy in rats, substantial evidence has revealed that ALR was a survival factor that protected the liver in the clinical context against damaging agents, such as ethanol, carbon tetrachloride, d-galactosamine and acetaminophen-induced liver injury $(18,28)$. Our previous research revealed that ALR 

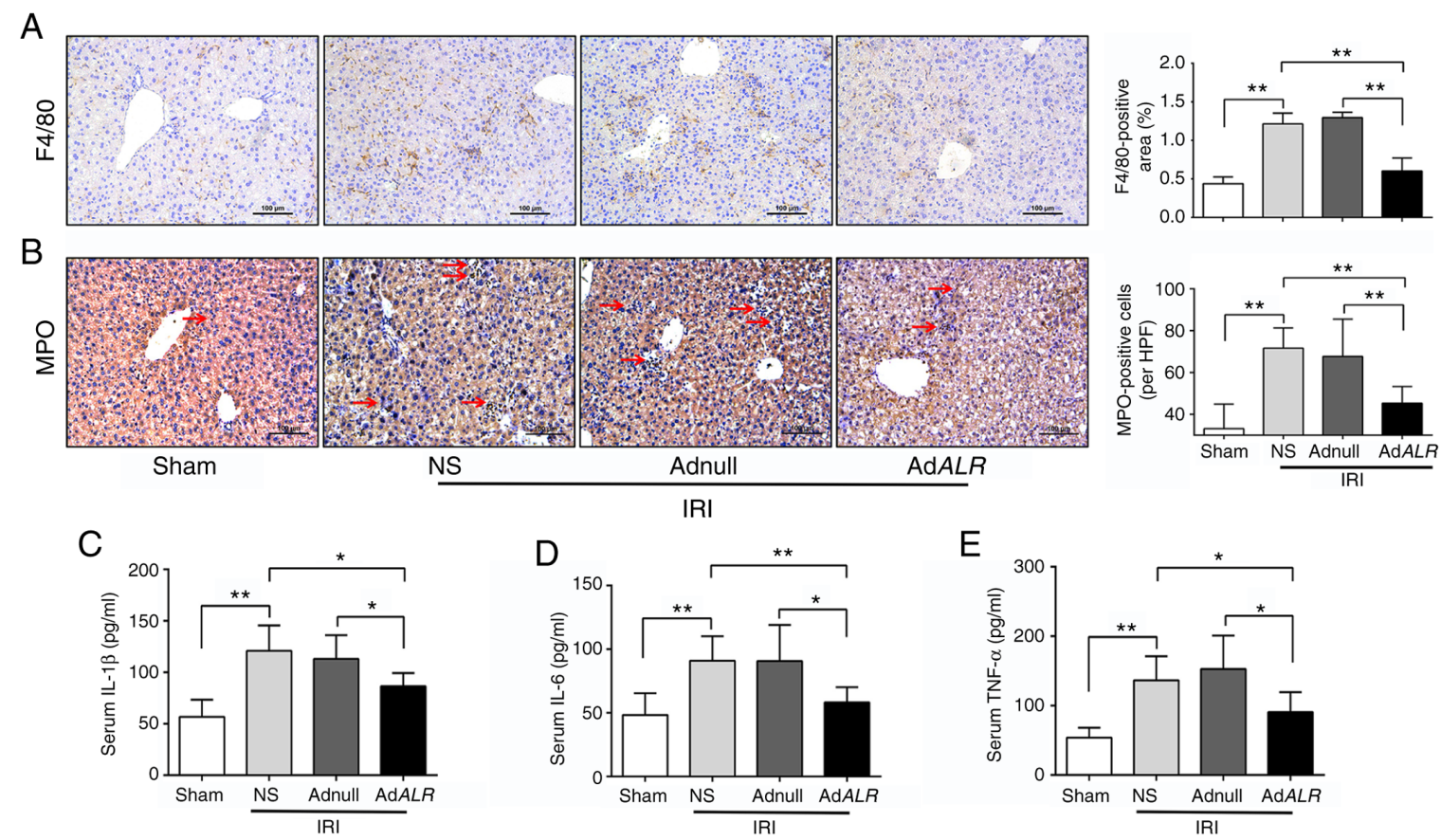

Figure 3. ALR administration inhibits the inflammatory response and decreases proinflammatory cytokines in steatotic livers after IRI.(A) Immunohistochemical staining of Kupffer cells was performed using an anti-F4/80 antibody in liver sections. (B) Neutrophil infiltration in liver tissues was detected using an anti-MPO antibody. (C-E) The serum levels of IL-1 $\beta$, IL-6 and TNF- $\alpha$ were assessed using ELISA. Scale bars, $100 \mu \mathrm{m}$. ${ }^{*} \mathrm{P}<0.05$ and ${ }^{* * *} \mathrm{P}<0.01 ; \mathrm{n}=6 \mathrm{per}$ group. ALR, augmenter of liver regeneration; IRI, ischemia-reperfusion injury; F4/80, EGF-like module-containing mucin-like hormone receptor-like 1; MPO, myeloperoxidase; IL, interleukin; TNF, tumor necrosis factor; NS, normal saline.
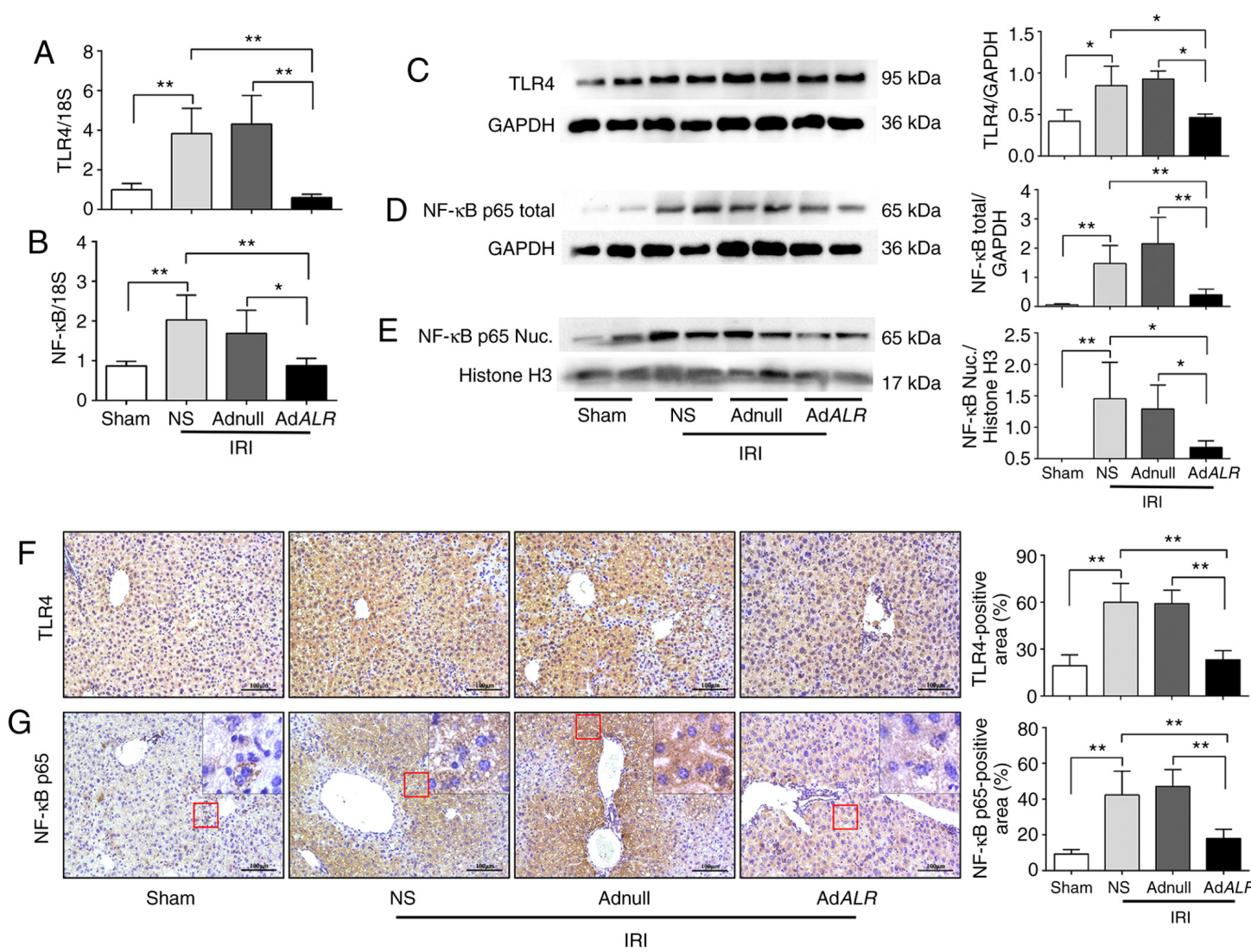

IR

Figure 4. ALR administration inhibits the TLR4/NF-KB signaling pathway in steatotic livers after IRI. C57BL/6 mice were fed a methionine-choline-deficient diet for 2 weeks then subjected to $30 \mathrm{~min}$ of ischemia followed by $6 \mathrm{~h}$ of reperfusion. (A and B) The mRNA levels of TLR4 and NF- $\mathrm{kB}$ p 65 were measured using reverse transcription-quantitative PCR, and 18S rRNA was used as the internal control. (C and D) The protein expression of TLR4 and NF- $\kappa B$ p65 was measured using western blotting. (E) The nuclear distribution of NF- $\mathrm{kB}$ p65 was detected by western blotting. (F and G) TLR4 and NF- $\mathrm{kB}$ levels were evaluated in liver sections using immunohistochemical staining. Scale bars, $100 \mu \mathrm{m}$. ${ }^{*} \mathrm{P}<0.05$ and ${ }^{* * *} \mathrm{P}<0.01 ; \mathrm{n}=6$ per group. ALR, augmenter of liver regeneration;

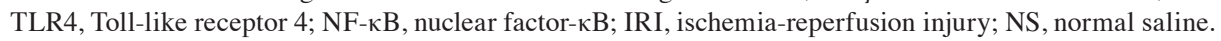


alleviated IRI in fatty livers by promoting mitochondrial function, reducing oxidative stress and enhancing antioxidant activity (21). Previous studies reported that ALR played an important role in the formation of fatty liver. Decreased ALR expression promoted fat accumulation in the liver of mice, and the ALR level in the serum of patients with steatohepatitis was also significantly reduced $(29,30)$. However, the regulatory effects of ALR on the inflammatory response in fatty liver IRI are not clear.

The expression of ALR after IRI in fatty livers was initially examined and it was revealed that IRI decreased ALR expression, which indicated that ALR depletion during fatty liver IRI was associated with aggravated liver injury. Adenovirus-mediated ALR transfection was used to detect the gain of function of ALR in fatty liver IRI. Our results indicated that ALR maintained liver function and alleviated liver injury, as indicated by the decreased ALT and AST levels, preserved hepatic structure, reduced apoptosis and increased hepatocyte proliferation.

Inflammation plays pivotal roles in hepatic IRI, especially in steatotic livers $(31,32)$. The cytosolic components and cell fragments released from the damaged liver trigger the production of IL-1 $\beta$, IL- 6 and TNF- $\alpha$, which are key proinflammatory mediators of hepatic IRI (22). KCs are liver-resident macrophages that become activated and release inflammatory mediators during the early phase of IRI. Neutrophils and monocytes migrate to and accumulate in the injured liver at later phases, which contribute to the additional, prolonged injury. An anti-inflammatory strategy of modulating the exaggerated inflammatory response to protect the liver against IRI was reported in numerous studies $(33,34)$.

ALR expression reduced the serum levels of inflammatory cytokines, such as IL- $1 \beta$, IL- 6 and TNF- $\alpha$, in the present study. Activation of KCs and neutrophil recruitment, as evaluated by staining for F4/80 and MPO, respectively, were inhibited by ALR expression in fatty liver IRI. Consistent with our results, Khandoga et al used intravital fluorescence microscopy and observed that ALR expression decreased the number of rolling and firmly adherent leukocytes in post-sinusoidal venules in normal hepatic IRI (19).

TLR4 is extensively expressed in liver cells, such as KCs and hepatocytes (13), and it is closely related to the development of hepatic IRI $(35,36)$. TLR4 triggers the activation and nuclear translocation of the transcription factor NF- $\kappa \mathrm{B}$, which culminates in the transcription of inflammatory cytokine genes (37). Blockade of TLR4 alleviates liver IRI by reducing neutrophil sequestration, $\mathrm{CD}^{+}{ }^{+} \mathrm{T}$ cell infiltration, and cytokine and chemokine production $(36,38)$.

The anti-inflammatory effects of ALR were demonstrated previously. Yan et al reported that ALR mitigated acute renal IRI in rats by reducing the protein expression of NF- $\kappa \mathrm{B}$, but the mechanism was not clear (39). Pan et al demonstrated that ALR alleviated acute pancreatitis via inhibition of the TLR4/NF- $\kappa$ B pathway and reduction of the release of TNF- $\alpha$ and cyclooxygenase-2 (COX-2) (40). These studies indicated that ALR is closely related to TLR4. In the present study, it was determined whether the regulatory role of ALR in inflammation in fatty liver IRI was mediated via the TLR4/NF- $\mathrm{B}$ pathway. Our results revealed that the TLR4/NF- $\kappa B$ signaling pathway was activated in fatty liver IRI, and ALR transfection provided a protective effect by decreasing the TLR4/NF- $\kappa \mathrm{B}$ signaling pathway.

There are some limitations in the present study. Although this study indicated that ALR inhibited the TLR4/NF- $\mathrm{B}$ signaling pathway, whether this regulation was direct or indirect remains unclear. The manner with which ALR regulates the expression of TLR4 and the identity of intermediate molecules that mediate the interaction between ALR and the TLR4/NF- $\kappa \mathrm{B}$ signaling pathway are not clear. Therefore, the regulation of ALR on the TLR4/NF- $\mathrm{B}$ signaling pathway in fatty liver IRI requires further in-depth research.

In conclusion, the present study demonstrated that the administration of ALR effectively alleviated hepatocyte apoptosis and preserved liver function by suppressing inflammatory cell infiltration and reducing inflammatory cytokine production. ALR played a role in the inflammatory response via the inhibition of the TLR4/NF- $\kappa \mathrm{B}$ signaling pathway in fatty liver IRI. Therefore, the anti-inflammatory effect of ALR establishes a promising strategy to protect steatotic livers against IRI.

\section{Acknowledgements}

Not applicable.

\section{Funding}

The present study was supported by the National Natural Science Foundation of China (grant no. 31371169) and the Beijing Tongzhou District Technology Plan (grant no. KJ2019CX014-21).

\section{Availability of data and materials}

The datasets used and/or analyzed during the present study are available from the corresponding authors on reasonable request.

\section{Authors' contributions}

JW designed and performed the experiments. JW, BX and WL analyzed and interpreted the data. XW established the mouse model and performed the in vivo experiments. BX and WL designed and supervised the study, wrote and revised the manuscript. All authors read and approved the final manuscript. JW and WL confirm the authenticity of all the raw data.

\section{Ethics approval and consent to participate}

All animal studies were approved by the Ethics Committee of Capital Medical University (Beijing, China; approval number AEEI-2016-094).

\section{Patient consent for publication}

Not applicable.

\section{Competing interests}

The authors declare that they have no competing interests. 


\section{References}

1. Fondevila C, Busuttil RW and Kupiec-Weglinski JW: Hepatic ischemia/reperfusion injury--a fresh look. Exp Mol Pathol 74 86-93, 2003.

2. Zhai Y, Petrowsky H, Hong JC, Busuttil RW and KupiecWeglinski JW: Ischaemia-reperfusion injury in liver transplantation - from bench to bedside. Nat Rev Gastroenterol Hepatol 10: 79-89, 2013.

3. Bzowej NH: Nonalcoholic steatohepatitis: The new frontier for liver transplantation. Curr Opin Organ Transplant 23: 169-174, 2018.

4. Besutti G, Valenti L, Ligabue G, Bassi MC, Pattacini P, Guaraldi G and Giorgi Rossi P: Accuracy of imaging methods for steatohepatitis diagnosis in non-alcoholic fatty liver disease patients: A systematic review. Liver Int 39: 1521-1534, 2019.

5. Tashiro H, Kuroda S, Mikuriya $\mathrm{Y}$ and Ohdan $\mathrm{H}$ : Ischemia-reperfusion injury in patients with fatty liver and the clinical impact of steatotic liver on hepatic surgery. Surg Today 44: 1611-1625, 2014

6. Maurice $\mathrm{J}$ and Manousou P: Non-alcoholic fatty liver disease. Clin Med (Lond) 18: 245-250, 2018.

7. Jiménez-Castro MB, Meroño N, Mendes-Braz M, Gracia-Sancho J, Martínez-Carreres L, Cornide-Petronio ME, Casillas-Ramirez A, Rodés J and Peralta C: The effect of brain death in rat steatotic and non-steatotic liver transplantation with previous ischemic preconditioning. J Hepatol 62: 83-91, 2015.

8. Kubes P and Mehal WZ: Sterile inflammation in the liver. Gastroenterology 143: 1158-1172, 2012.

9. Yang F, Shang L, Wang S, Liu Y, Ren H, Zhu W and Shi X: $\mathrm{TNF} \alpha$-mediated necroptosis aggravates ischemia-reperfusion injury in the fatty liver by regulating the inflammatory response. Oxid Med Cell Longev 2019: 2301903, 2019.

10. Li Y, Ma D, Wang Z and Yang J: MicroRNA-155 deficiency in Kupffer cells ameliorates liver ischemia-reperfusion injury in mice. Transplantation 101: 1600-1608, 2017.

11. Schwabe RF, Seki E and Brenner DA: Toll-like receptor signaling in the liver. Gastroenterology 130: 1886-1900, 2006.

12. Rao J, Qian X, Li G, Pan X, Zhang C, Zhang F, Zhai Y, Wang X and Lu L: ATF3-mediated NRF2/HO-1 signaling regulates TLR4 innate immune responses in mouse liver ischemia/reperfusion injury. Am J Transplant 15: 76-87, 2015.

13. Zhai Y, Busuttil RW and Kupiec-Weglinski JW: Liver ischemia and reperfusion injury: New insights into mechanisms of innate-adaptive immune-mediated tissue inflammation. Am J Transplant 11: 1563-1569, 2011.

14. Lv YN, Ou-Yang AJ and Fu LS: MicroRNA-27a negatively modulates the inflammatory response in lipopolysaccharide-stimulated microglia by targeting TLR4 and IRAK4. Cell Mol Neurobiol 37: 195-210, 2017.

15. Jiang X, Kuang G, Gong X, Jiang R, Xie T, Tie H, Wu S, Wang T, Wan J and Wang B: Glycyrrhetinic acid pretreatment attenuates liver ischemia/reperfusion injury via inhibiting TLR4 signaling cascade in mice. Int Immunopharmacol 76: 105870, 2019.

16. LaBrecque DR and Pesch LA: Preparation and partial characterization of hepatic regenerative stimulator substance (SS) from rat liver. J Physiol 248: 273-284, 1975.

17. Zhang J, Li Y, Jiang S, Yu H and An W: Enhanced endoplasmic reticulum SERCA activity by overexpression of hepatic stimulator substance gene prevents hepatic cells from ER stress-induced apoptosis. Am J Physiol Cell Physiol 306: C279-C290, 2014.

18. Thirunavukkarasu C, Wang LF, Harvey SA, Watkins SC, Chaillet JR, Prelich J, Starzl TE and Gandhi CR: Augmenter of liver regeneration: An important intracellular survival factor for hepatocytes. J Hepatol 48: 578-588, 2008

19. Khandoga A, Mende K, Iskandarov E, Rosentreter D, Schelcher C, Reifart J, Jauch KW and Thasler WE: Augmenter of liver regeneration attenuates inflammatory response in the postischemic mouse liver in vivo. J Surg Res 192: 187-194, 2014

20. Care NRCU and Animals AUOL: Guide for the Care and Use of Laboratory Animals. National Academies Press, Washington, DC, 2011.

21. Weng J,Li W,Jia X and An W: Alleviation of Ischemia-Reperfusion Injury in Liver Steatosis by Augmenter of Liver Regeneration Is Attributed to Antioxidation and Preservation of Mitochondria. Transplantation 101: 2340-2348, 2017.

22. Olthof PB, van Golen RF, Meijer B, van Beek AA, Bennink RJ, Verheij J, van Gulik TM and Heger M: Warm ischemia time-dependent variation in liver damage, inflammation, and function in hepatic ischemia/reperfusion injury. Biochim Biophys Acta Mol Basis Dis 1863: 375-385, 2017.
23. Suzuki S, Toledo-Pereyra LH, Rodriguez FJ and Cejalvo D: Neutrophil infiltration as an important factor in liver ischemia and reperfusion injury. Modulating effects of FK506 and cyclosporine. Transplantation 55: 1265-1272, 1993.

24. Livak KJ and Schmittgen TD: Analysis of relative gene expression data using real-time quantitative PCR and the 2(-Delta Delta $\mathrm{C}(\mathrm{T})$ ) method. Methods 25: 402-408, 2001

25. van der Veen BS, de Winther MP and Heeringa $P$. Myeloperoxidase: Molecular mechanisms of action and their relevance to human health and disease. Antioxid Redox Signal 11: 2899-2937, 2009.

26. Colletti LM, Kunkel SL, Walz A, Burdick MD, Kunkel RG, Wilke CA and Strieter RM: The role of cytokine networks in the local liver injury following hepatic ischemia/reperfusion in the rat. Hepatology 23: 506-514, 1996.

27. Nace GW, Huang H, Klune JR, Eid RE, Rosborough BR, Korff S, Li S, Shapiro RA, Stolz DB, Sodhi CP, et al: Cellular-specific role of toll-like receptor 4 in hepatic ischemia-reperfusion injury in mice. Hepatology 58: 374-387, 2013.

28. Liu L, Xie P, Li W, Wu Y and An W: Augmenter of liver regeneration protects against ethanol-induced acute liver injury by promoting autophagy. Am J Pathol 189: 552-567, 2019.

29. Maehara Y and Fernandez-Checa JC: Augmenter of liver regeneration links mitochondrial function to steatohepatitis and hepatocellular carcinoma. Gastroenterology 148: 285-288, 2015.

30. Kumar S, Verma AK, Rani R, Sharma A, Wang J, Shah SA, Behari J, Salazar Gonzalez R, Kohli R and Gandhi CR: Hepatic deficiency of augmenter of liver regeneration predisposes to nonalcoholic steatohepatitis and fibrosis. Hepatology 72 1586-1604, 2020

31. Nakamura K, Zhang M, Kageyama S, Ke B, Fujii T, Sosa RA, Reed EF, Datta N, Zarrinpar A, Busuttil RW, et al: Macrophage heme oxygenase-1-SIRT1-p53 axis regulates sterile inflammation in liver ischemia-reperfusion injury. J Hepatol 67: 1232-1242, 2017.

32. Jimenez-Castro MB, Cornide-Petronio ME, Gracia-Sancho J and Peralta C: Inflammasome-mediated inflammation in liver ischemia-reperfusion injury. Cells 8: 1131, 2019.

33. Nakamura K, Zhang M, Kageyama S, Ke B, Fujii T, Sosa RA, Reed EF, Datta N, Zarrinpar A, Busuttil RW, et al: Macrophage heme oxygenase-1-SIRT1-p53 ax is regulates sterile inflammation in liver ischemia-reperfusion injury. J Hepatol 67: 1232-1242, 2017.

34. Motiño O, Francés DE, Casanova N, Fuertes-Agudo M, Cucarella C, Flores JM, Vallejo-Cremades MT, Olmedilla L, Pérez Peña J, Bañares R, et al: Protective role of hepatocyte cyclooxygenase-2 expression against liver ischemia-reperfusion injury in mice. Hepatology 70: 650-665, 2019.

35. Ben-AriZ, Avlas O, Fallach R, Schmilovitz-Weiss H, Chepurko Y, Pappo O and Hochhauser E: Ischemia and reperfusion liver injury is reduced in the absence of Toll-like receptor 4. Cell Physiol Biochem 30: 489-498, 2012.

36. Shen XD, Ke B, Zhai Y, Gao F, Tsuchihashi S, Lassman CR, Busuttil RW and Kupiec-Weglinski JW: Absence of toll-like receptor 4 (TLR4) signaling in the donor organ reduces ischemia and reperfusion injury in a murine liver transplantation model. Liver Transpl 13: 1435-1443, 2007.

37. Li X: IRAK4 in TLR/IL-1R signaling: Possible clinical applications. Eur J Immunol 38: 614-618, 2008

38. Jiang N, Zhang X, Zheng X, Chen D, Zhang Y, Siu LK, Xin HB, Li R, Zhao H, Riordan N, et al: Targeted gene silencing of TLR4 using liposomal nanoparticles for preventing liver ischemia reperfusion injury. Am J Transplant 11: 1835-1844, 2011.

39. Yan R, Li Y, Zhang L, Xia N, Liu Q, Sun H and Guo H: Augmenter of liver regeneration attenuates inflammation of renal ischemia/reperfusion injury through the NF-kappa B pathway in rats. Int Urol Nephrol 47: 861-868, 2015.

40. Pan LF, Yu L, Wang LM, He JT, Sun JL, Wang XB, Wang H, Bai ZH, Feng $\mathrm{H}$ and Pei $\mathrm{HH}$ : Augmenter of liver regeneration (ALR) regulates acute pancreatitis via inhibiting HMGB1/TLR4/ NF- $\kappa B$ signaling pathway. Am J Transl Res 10: 402-410, 2018.

This work is licensed under a Creative Commons Attribution-NonCommercial-NoDerivatives 4.0 International (CC BY-NC-ND 4.0) License. 